\title{
Attenuation Studies of Booster-Rocket Propellants and Their Simulants
}

\author{
Larry J. Weirick \\ Explosive Projects and Diagnostics Division \\ Sandia National Laboratories \\ Albuquerque, New Mexico 87185
}

\begin{abstract}
A series of impact experiments on a composite propellant, an energetic propellant, and their simulants was recently completed using a light-gas gun. Previous experiments ${ }^{1}$ were done to obtain Hugoniot data, to investigate the pressure threshold at which a reaction occurs, and to measure spall damage at various impact velocities. The present studies measured the attenuation of shock waves in these materials, completing the shock characterization needed for material modeling. An initial impulse of $2.0 \mathrm{GPa}$ magnitude and $\sim 0.6 \mu$ s duration was imposer! upon samples of various thicknesses. VISAR was used to measure the free-surface velocity at the back of the samples; these data were used to generate a curve of shock-wave attenuation versus sample thickness for each material. Results showed that all four materials attentated the shock wave very similarly. Material thicknesses of $3.0,7.62,12.7$, anc $19.0 \mathrm{~mm}$ attenuated the shock wave $\sim 16^{\prime} \prime, 33^{\prime} \%, 50^{\prime} \%$, and $66^{\circ}$, , respectively.
\end{abstract}




\section{Acknowledgements}

The author gratefully acknowledges the contributions of the following people, without whose assistance this program would not have been possible: John Matthews, 2514, who set up and operated the diagnostics and built the propellant targets; Mike Navarro, K-Tech Corp., who operated the gas gun; Heidi Anderson, K-Tech Corp., who built the projectiles and the simulant targets; Al McDonald, 8242, who initiated the program's need and provided program direction and liaison; Lloyd Bonzon, 2514, who gave managerial support, direction, and encouragement; Agries Greb, K-Tech Corp., who was invaluable in instructing the author on transmission shots in general and attenuation shots in particular; and Bruce Kistler, 8242 , who improved this paper considerably by his many explanations and discussions. 


\section{Contents}

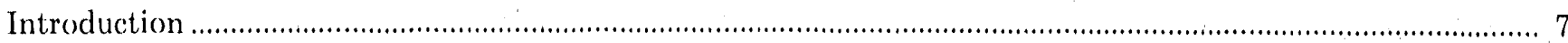

Experimental Procedure

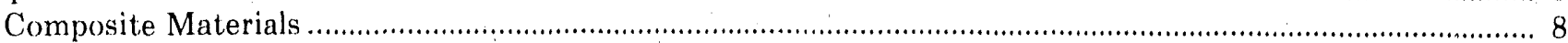

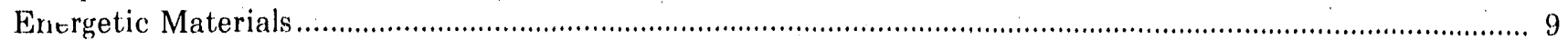

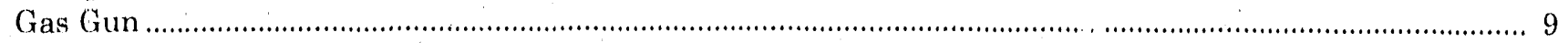

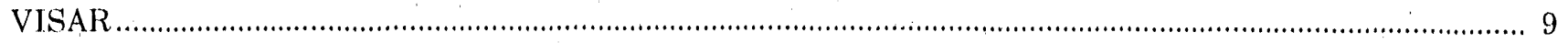

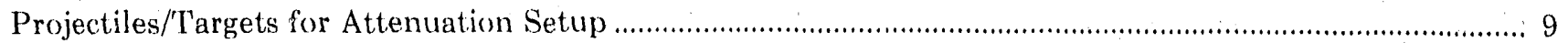

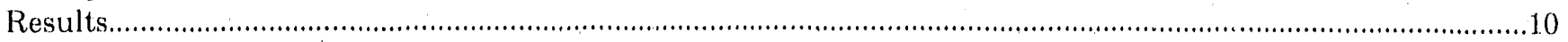

Overall

H-19

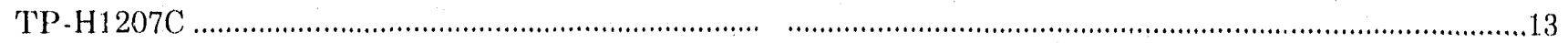

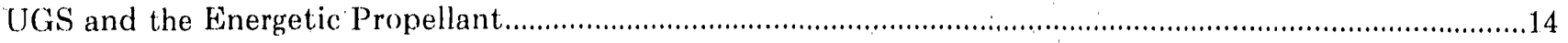

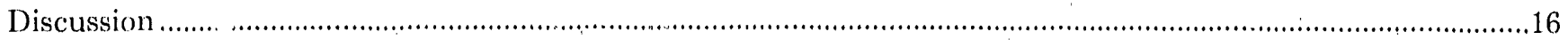

Summarv

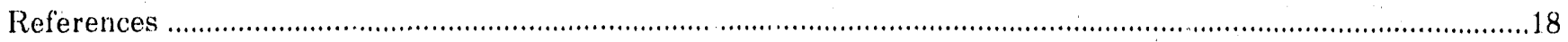

\section{Figures}

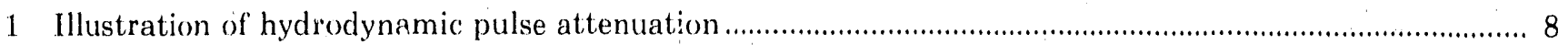

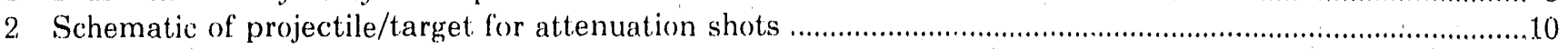

3 Plot of free-surface velocity with time for H-19 samples of various thicknesses ….....................................12

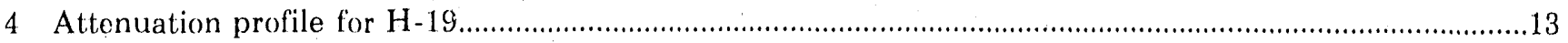

5 Plot of free-surface velocity with time for TP-H1207C samples of various thicknesses..............................13

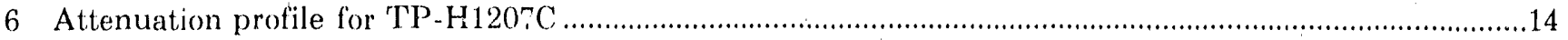

7 Plot of free-surface velocity with time for UGS samples of various thicknesses ........................................14

8 ?lot of free-surface velocity with time for the energetic propellant samples of various thickness ...............15

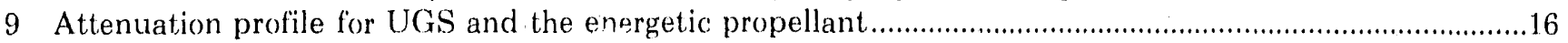

10 Atteruation profiles for H-19, TP-H1207C, UGS, and the energetic propellant .........................................16

11 Particle velocity at the front and rear of the H-19 target (SRI) ...........................................................16

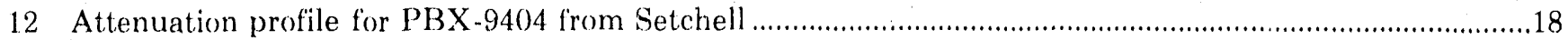

\section{Tables}

1 Composite Formulations and Mechanical Properties ................................................................................ 8

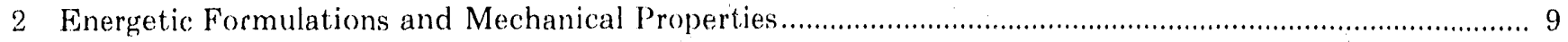

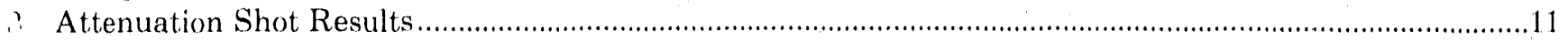

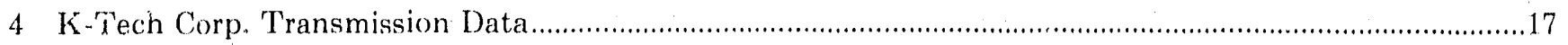




\section{Attenuation Studies of Booster-Rocket Propellants and Their Simulants}

\section{Introduction}

'This investigation was begun to aid in studies of' the vulnerability and lethality of solid-propellant. booster stages. The materials of interest are a composite propellant, an energetic propellant, and their simulants. Better characterization of the inert simulants will allow their use in testing wherever possible.

The shock Hugoniot of a material is determined by the relationship between the shock and particle velocities. This relationship can be determined experimentally from planar, gun-impact experiments and can for many materials be approximated by a linear fit:

$\mathrm{U}_{\mathrm{s}}=\mathrm{C}_{0}+\mathrm{SU}_{\mathrm{p}}$

where $U_{s}$ is the shock velocity, $C_{0}$ is the initial bulk sound velocity, $S$ is a constant, and $U_{p}$ is the particle velocity.

The shock Hugoniots of the composite and energetic propellants, and their simulants, were reported in an earlier paper. 'To summarize here, the values of' initial density, $\rho_{0}$, initial bulk sound velocity, $C_{0}$, and $\mathrm{S}$ are $1.84 \mathrm{~g} / \mathrm{cm}^{3}, 2.3 \mathrm{~mm} / \mu \mathrm{s}$, and 2.16 , respectively, for T'P-H1207C; $1.89 \mathrm{~g} / \mathrm{cm}^{3}, 2.25 \mathrm{~mm} / \mu \mathrm{s}$, and 1.5 , respectively, for H-19; and $1.85 \mathrm{~g} / \mathrm{cm}^{3}, 2.2 \mathrm{~mm} / \mu \mathrm{s}$, and 2.66 , respectively, for the energetic propellant and its simulant, UGS.

The detonability of composite propellants has been studied since their inception. A recent study was done at Lawrence Livermore National Laboratory ${ }^{2}$ (LiLNL) on the detonability of a composite propellant. Delayed explosions were observed in the impactdamaged propellant at impact pressures above 3.0 GPa. The pressure threshold for a reaction to initiate in the composite propellant TP-H1207C was found to be $\sim 4.0$ GPa.

The sensitivity and power of energetic propellants were studied in the 1970s at LI.NL." This work, together with investigations by SRI International and others, was summarized in a report from the HighEnergy Propellant Safety (HEPS) Committee. ${ }^{4}$ More recently, a study was done at LL.NL on the detonability of energetic propellants. ${ }^{5}$ They found a delayed det. onation threshold of $0.62 \mathrm{GPa}$ and a shock detonation threshold of 1.32 GPa for the most energetic of these propellants. The pressure threshold for a reaction to proceed in the energetic propellant from a direct impact was found to be above $0.53 \mathrm{GPa}$, but below $0.91 \mathrm{GPa} .{ }^{1}$ The detonation threshold was est mated to be $\sim 2.0$ GPa.!

The process of spallation has been studied in a number of laboratories with a view to obtaining the criteria for dynamic fracture at high stress rate. 'Tension is induced within a sample by allowing a stress wave to reflect as a rarefaction from a free surface. The tension increases by interaction of the rarefaction wave with the primary wave until a critical value is reached and fracture occurs. The fact that the free-surface velocity stops dropping and then rises ("spall rebound or pullback") is due to the generation of compressive waves at the spall pla:se that increase the pressure. 'The clearly defined onset of fracture at a specific value of pullback suggests a characteristic material strength that corresponds to a damage threshold tension. This material property is referred to as the incipient fracture strength or spall strength, $\sigma$. The value of $\sigma$ may be approximately related to the observed pullback by considering the interaction of the reflected wave with the primary wave, assuming a perfect reflection at the free surfaces. ${ }^{6}$ The resultant expression is:

$\sigma=1 / 2 \mathrm{C}_{0} / \rho_{0} \Delta \mu$

where $C_{0}$ is the initial bulk sound velocity, $\rho_{0}$ is the material density, and $\Delta \mu$ is the measured pullback. 'The incipient fracture is understood in material terms as the macroscopic yield stress necessary for the growth of internal voids into a free surface or spall plane. The spall strengths of 'TP..H1207C and H-19 were measured as 0.022 and $0.018 \mathrm{GPa}$, respectively, and of the energetic propellant and UGS as 0.033 and 0.022 GPa, respectively.'

It is generally well known that a square pulse, introduced at the surface of a material that will not 
support a shear wave, evolves to a triangular pulse as 'it propagates through the material (Figure 1). The speed of propagation of the front is associated with the slope of the Rayleigh line and, in the absence of viscosity, this front propagates as a shock. The rarefraction wave, on the other hand, is governed by a reversible adiabatic process where the sound speed immediately behind the shock front is greater than the shock velocity and decreases with decreasing pressure. The result is that the peak pressure and the slope of the expansion wave both clecrease with propagation distance and the length of the pulse increases. This phenomenon, called hydrodynamic at.. tenuation, is exhibited by most materials.

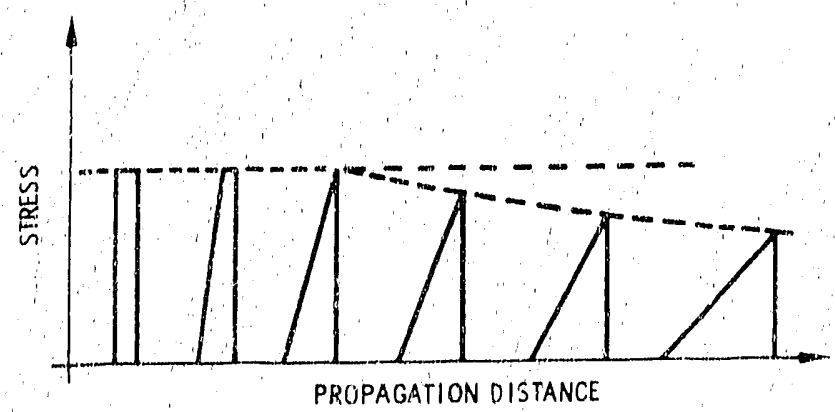

Figure 1. Illustration of hydrodynamic pulse attenuation

The objective of the present study is to obtain attenuation data for the two propeliants and their simulants. This information is needed in order for a complete materials model to be used in a code called WONDY. ${ }^{7}$ WONDY can then be used to predict the axtent of propellant spallation on the inside of a propellant core in a rocket booster that has been shocked by a laser be am.

\section{Experimental Procedure}

\section{Composite Materials}

One propellant, TP-H1207C, and its simulant, $\mathrm{H}-19$, are of composite formulation, and the other propellant, the energetic and its simulant, UGS, are based upon energetic formulations, as given in T'ables 1 and $2 i^{8}$ None of the materials have any significant porosity. 'The $\mathrm{H}-19$ contains large, rectangular crystals of potassium chloride and small, spherically shaped particles of metallic aluminum. The matrix that binds these constituents together is an hydroxyterminated, polybutadiene-polyurethane polymer (H'TPB). The TP-H1207C propellant formulation is based upon ammonium perchlorate with aluminum additions and bound together with the HTPB. The "static" mechanical properties of these materials are given in Table 1 . The tensile strengths are relatively low $(\sim 0.001 \mathrm{GPa})$ and the elongations are moderate ( $\sim 500^{\prime \prime}$ i). Densities of $\sim 1.8 \mathrm{~g} / \mathrm{cm}^{3}$ are typical of solid propellants.

\section{Table 1. Composite Formulations and Mechanical Properties}

\begin{tabular}{|c|c|c|c|}
\hline $1 \quad 1$ & TP-H1207C & \multicolumn{2}{|c|}{$\mathrm{H}-19$ (wt. "i) } \\
\hline \multicolumn{4}{|l|}{ Composition: } \\
\hline Fuel ": & Aluminum & $\mathrm{Al}$ & 31.75 \\
\hline Oxidizer & Ammonium perchlorate & $\mathrm{AP}$ & 5.0 \\
\hline Inerts & & $\mathrm{KCl}$ & 51.5 \\
\hline Polymars & $\begin{array}{l}\text { Hydroxy-terminated } \\
\text { poiybutadiene }\end{array}$ & HTPB & 8.8 \\
\hline Curatives & & IPDI & 0.7 \\
\hline Plasticizer & & DOA & 2.0 \\
\hline Bonding agent & & Tepanol & 0.2 \\
\hline Processing aid & & ODI & 0.04 \\
\hline Cure catalyst & & TPB & 0.02 \\
\hline \multicolumn{4}{|l|}{ Mechanical Properties: } \\
\hline Density $\left(\mathrm{g} / \mathrm{cm}^{3}\right)$ & 1.84 & \multicolumn{2}{|c|}{1.89} \\
\hline Tensile strength (psi/GPa) & $140.0 / 0.001$ & \multicolumn{2}{|c|}{$114.0 / 0.008$} \\
\hline Maximum elongation ("i) & 45.3 & \multicolumn{2}{|c|}{32.0} \\
\hline Tensile modulus (psi) & 637.0 & \multicolumn{2}{|c|}{450.0} \\
\hline
\end{tabular}




\section{Table 2. Energetic Formulations and Mechanical Properties}

\begin{tabular}{|c|c|c|c|}
\hline & Energetic & \multicolumn{2}{|c|}{ UGS (wt. 器) } \\
\hline \multicolumn{4}{|l|}{ Composition: } \\
\hline \multirow[t]{2}{*}{ Fuel } & Double-base propellant & $\mathrm{DBP}$ & 19.7 \\
\hline & Aluminum & $\mathrm{Al}$ & 5.0 \\
\hline \multirow[t]{2}{*}{ Oxidizer } & $\mathrm{HMX}$ & HMX & 0.0 \\
\hline & Ammonium perchlorate & AP & 0.0 \\
\hline Inerts & & $\mathrm{NaSO}_{4}$ & 65.3 \\
\hline Polymers & & HDAP & 9.0 \\
\hline Curatives & & $\mathrm{N} 100$ & 1.0 \\
\hline Processing aid & & HDI & 0.04 \\
\hline
\end{tabular}

\section{Mechanical Properties:}

\author{
Density $\left(\mathrm{g} / \mathrm{cm}^{3}\right)$ \\ Tensile strength (psi/GPa) \\ Maximum elongation ("i) \\ Tensile modulus (psi)
}

\subsection{5}

$100.0 / 0.0007$

250.0

450.0
1.85

$158.0 / 0.011$

50.0

490.0

\section{Energetic Materials}

The energetic propellant formulation is based upon a double-base mix of nitrocellulose and nitroglycerin. It also contains aluminum and HMX. The UGS simulant contains large, rectangular crystals of sodium sulphate and small, spherically shaped particles of aluminum. The matrix that binds these constituents together is a mix of hexane, diol, adipate, and phythalate (HDAP) and the double-base propellant. The "static" mechanical properties of these materials are given in Table 2. The tensile strength of these materials is very low (near $0.001 \mathrm{GPa}$ ). The elongation value for the simulant UGS is moderate at 50 "': and the value for the energetic propellant is relatively high at $250 \%$. Densities near $1.85 \mathrm{~g} / \mathrm{cm}^{i 3}$ are typical of solid rocket booster propellants.

\section{Gas Gun}

The light-gas gun system used has previously been described in detail. ${ }^{9}$ Briefly, the barrel is $9 \mathrm{~m}$ long, with an inside diameter of $63.4 \mathrm{~mm}$. The breech is of a quick-acting, quick-change design with two inserts. One is termed a "wraparound" for low-velocity shots using nitrogen (below $0.5 \mathrm{~km} / \mathrm{s}$ ). A second is called a "dual-diaphragm" for higher-velocity shots using helium (up to $1.5 \mathrm{~km} / \mathrm{s}$ for projectiles with weights below $0.2 \mathrm{~kg}$ ).

\section{VISAR}

One modern technique used for measurement of shock phenomena is the VISAR (Velocity Interfero- meter System for Any Reflector). ${ }^{10}$ A "Push-Pull" VISAR method developed by Hemsing " and used in these experiments results in effective cancellation of self-light from a reaction. An important variation on the Push-Pull. VISAR is a system that has an $\mathrm{x} x$ tended (166 cm long) air.delay leg in place of the quartz.delay leg. This replacement allows the accurate measurement of particle velocity in a very low velocity regime (below $0.1 \mathrm{~km} / \mathrm{s}$ ).

\section{Projectiles/'Targets for Attenuation Setup}

Figure 2 is a schematic of the projectile and target configurations for these attenuation experiments. A 5 -cm-diameter sample of propellant/simulant was epoxied to an aluminum ring holder on the target mount. Sample thicknesses were $2.54,5.08,7.62$, $10.16,12.7$, and $19.05 \mathrm{~mm}$. A $0.01-\mathrm{mm}$-thick piece of aluminum foil was epoxied with urethane cement to the back side of the propellant/simulant disk to function as a reflecting mirror for the laser beam. This mirror was considered a "free surface." 'The projectiles were made from aluminum and had a 1-mm-thick PMMA disk (low-impedance impactor) attached to a $6.35-\mathrm{mm}$.long aluminum stand off ring at the front of the projectile. A 6.35 -mm-thick piece of low-density carbon foam was epoxied between the PMMA and aluminum projectile to function as a mechanical support for the thin PMMA disk as well as a spacer from the aluminum projectile. 
PROJECTILE

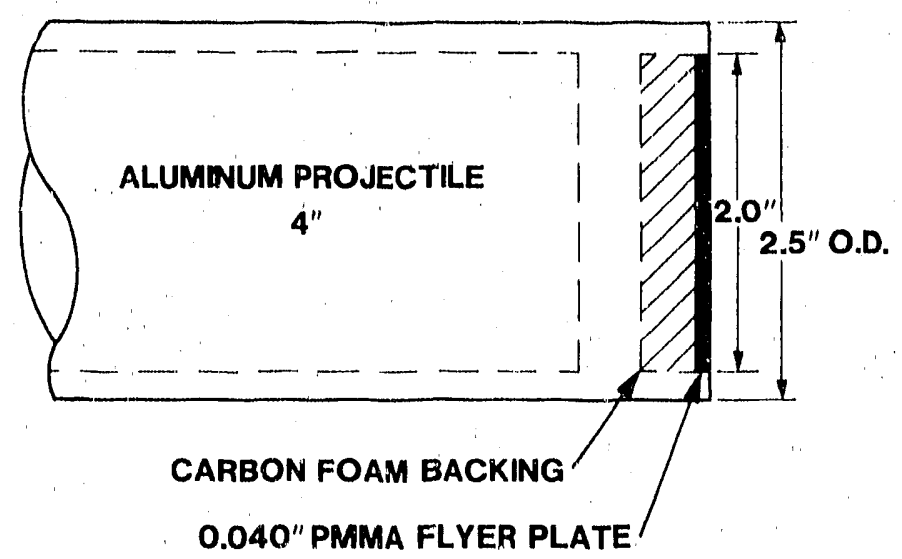

TARGET

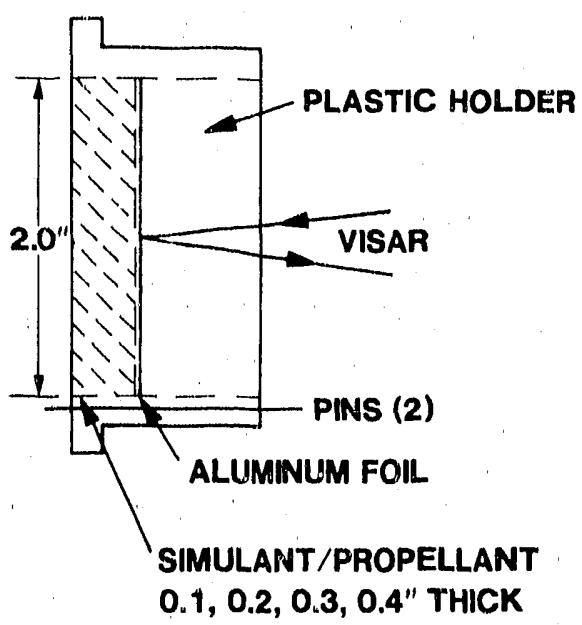

Figure 2. Schematic of projectile/target for attenuation shots

\section{Results}

\section{Overall}

A summary of the initial material conditions and final results for the attenuation experiments is given in Table 3. The information in the table includes the shot number; the measured thickness of the PMMA flyer plate; the measured thickness of the propellant/ simulant target; the measured thickness of the carbon foam backing material: the measured velocity of the aluminum projectile; the measured and, if different, the calculated transit time for the passage of the shock wave through the sample; and the measured free-surface velocity and corresponding pressure calculated from Hugoniot data. 


\begin{tabular}{|c|c|c|c|c|c|c|c|}
\hline $\begin{array}{l}\text { Shot } \\
\text { No. }\end{array}$ & $\begin{array}{l}\text { Flyer } \\
\text { Thickness } \\
(\mathrm{mm})\end{array}$ & $\begin{array}{l}\text { Target } \\
\text { Thickness } \\
(\mathrm{mm})\end{array}$ & $\begin{array}{l}\text { Target } \\
\text { Backing }\end{array}$ & $\begin{array}{l}\text { Projection } \\
\text { Velocity } \\
(\mathrm{mm} / \mu \mathrm{s}) \\
\end{array}$ & $\begin{array}{l}\text { Transit } \\
\text { Time } \\
(\mu \mathrm{s})\end{array}$ & $\begin{array}{l}\text { Free- } \\
\text { Surface } \\
\text { Velocity } \\
(\mathrm{mm} / \mu \mathrm{s})\end{array}$ & $\begin{array}{l}\text { Rear- } \\
\text { Surface } \\
\text { Pressure } \\
\text { (GPa) }\end{array}$ \\
\hline \multicolumn{8}{|c|}{$H-19$} \\
\hline 226 & $1.168^{*}$ & 07.62 & None & 0.871 & 2.71 & 0.57 & $\mathrm{NA}$ \\
\hline 227 & 1.092 & 10.16 & None & 0.840 & 3.59 & 0.46 & 1.12 \\
\hline 228 & 1.067 & 05.08 & $\mathrm{CF}^{+}+$ & 0.850 & 1.80 & 0.62 & 1.59 \\
\hline 229 & 1.016 & 02.54 & $\mathrm{CF}$ & 0.850 & 0.90 & 0.70 & 1.83 \\
\hline 240 & 1.016 & 07.62 & None & 0.857 & 2.71 & 0.51 & 1.26 \\
\hline \multicolumn{8}{|l|}{$U G S_{:}$} \\
\hline 230 & 1.016 & 07.11 & $\mathrm{CF}$ & 0.846 & $2.53 / 2.29$ & 0.50 & 1.32 \\
\hline 231 & 1.016 & 12.45 & $\mathrm{CF}$ & 0.854 & $4.49 / 3.96$ & 0.39 & 0.98 \\
\hline \multicolumn{8}{|c|}{$T P-H 1207 C:$} \\
\hline 233 & 1.016 & 12.70 & None & 0.852 & 4.21 & 0.45 & 1.16 \\
\hline 234 & 1.016 & 07.62 & None & 0.850 & 2.45 & 0.56 & 1.49 \\
\hline 235 & 1.016 & 10.16 & None & 0.854 & 3.28 & $0.47 \$$ & NA \\
\hline 236 & 1.016 & 05.08 & None & 0.856 & 1.65 & 0.65 & 1.79 \\
\hline 237 & 1.016 & 02.54 & None & 0.843 & 0.83 & 0.70 & 1.98 \\
\hline 239 & 1.016 & 19.05 & None & 0.858 & 6.20 & 0.32 & 0.77 \\
\hline \multicolumn{8}{|c|}{ Energetic: } \\
\hline 238 & 1.016 & 12.70 & None & 0.840 & $4.47 / 4.03$ & 0.39 & 0.98 \\
\hline 241 & 1.016 & 07.62 & None & 0.867 & $2.90 / 2.42$ & $0.61 \ddagger$ & 1.60 \\
\hline \multicolumn{8}{|c|}{$\begin{array}{l}\text { *Flyer thickness greater than normal } \\
+\mathrm{CF}-6.35 \mathrm{~mm} \text { carbon foam, } \rho_{12}=0.2 \mathrm{~g} / \mathrm{cm}^{3} \\
\text { †3ad data point. }\end{array}$} \\
\hline
\end{tabular}




\section{H-19}

Figure 3 shows the results from the attenuation experiments on four $\mathrm{H}-19$ samples with nominal thicknesses of $2.54,5.0,7.62$, and $10.16 \mathrm{~mm}(0.1,0.2$, 0.3 , and $0.4 \mathrm{in.}$ ), respectively. Zero time is set at impact. The free-surface velocity was measured at the back of the samples using the VISAR system. The transit times measured for the passage of the shook wave through these $H-19$ samples agree with values calculated from Hugoniot data for the corresponding sample thicknesses. Although the velocity profiles seem to indicate that there was no unloading of the samples after passage of the shock wave, the correct interpretation is that the back of the sample spalled and the VISAR measured the spall pieces flying away at velocities initially equivalent to twice the particle velocity.

Using the Hugoniot data previously obtained for $\mathrm{H}+19^{l}$ and the maximum free-surface velocities shown in Figure 3 ; the corresponding rear-surface pressure for a given sample thickness can be determined. These data are shown in Figure 4 and make up the attenuation profile for $\mathrm{H}-19$. The nominal value for the initial impact pressure for each of the samples is also shown in the figure.

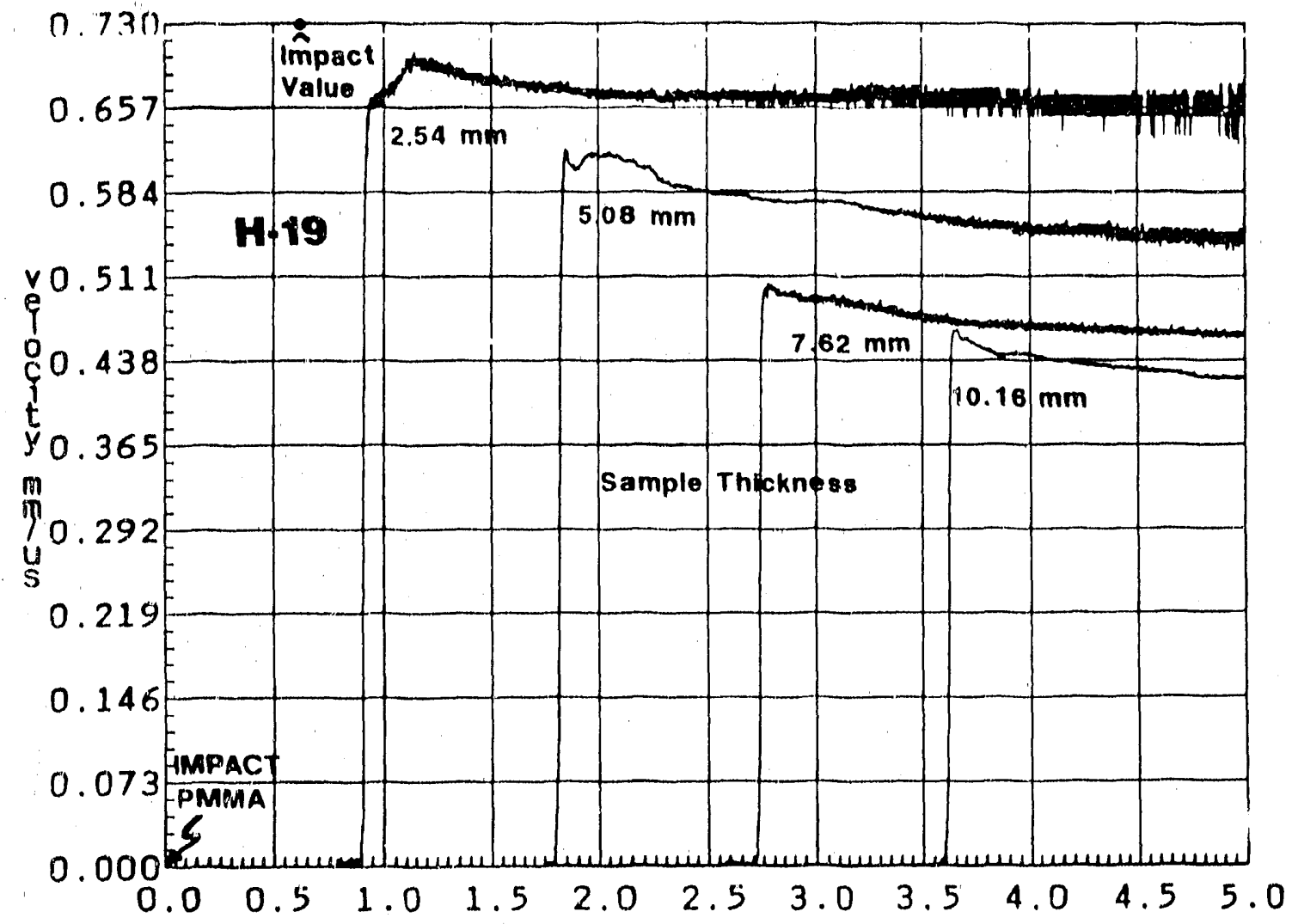

DAT: hp $1201 . v 27$

DAT: hp $1201 . \vee 28$

time, usec

DAT: hp1201.v29

DAT:hp1201.v40

$$
\begin{gathered}
11-0 C T-89 \\
03: 10: 12
\end{gathered}
$$

Figure 3. Plot of free-surface velocity with time for $\mathrm{H}-19$ samples of various thicknesses 


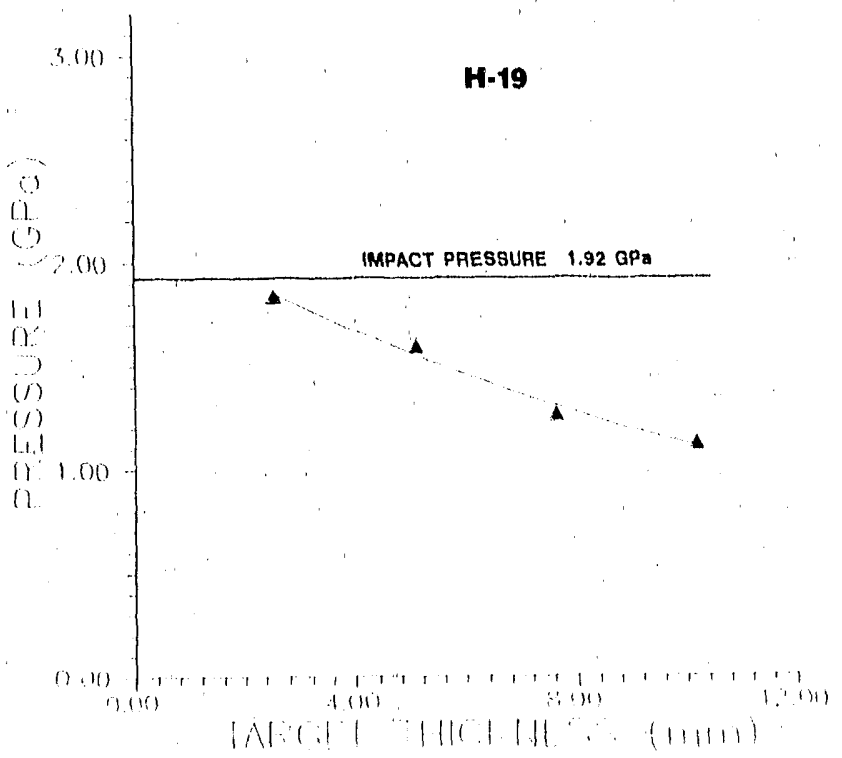

\section{TP-H1207C}

The results from the attenuation experiments on five TP-H1207C samples are shown in Figure 5. The TP. H $1207 \mathrm{C}$ samples had nominal thicknesses of 2.54 , $5.08,7.62,12.70$, and $19.05 \mathrm{~mm}(0.1,0.2,0.3,0.5$, and $0.75 \mathrm{in}$.$) , respectively. Zero time is set at impact. The$ transit times measured for passage of the shock wave through these IP. H1207C samples agree with values calculated from Hugoniot data for the corresponding sample thicknesses. Again, the velocity profile reflects the movement of the back of the sample away from the primary piece after spallation. 'The maximum value of the free-surface velocity is twice the equilibrium particle velocity. Using these values of particle velocity and Hugoniot data, the equilibrium rearsurface pressure can be calculated. The attenuation profile for 'TP-H1207C is shown in Figure 6.

Figure 4. Attenuation profile for $\mathrm{H}-19$

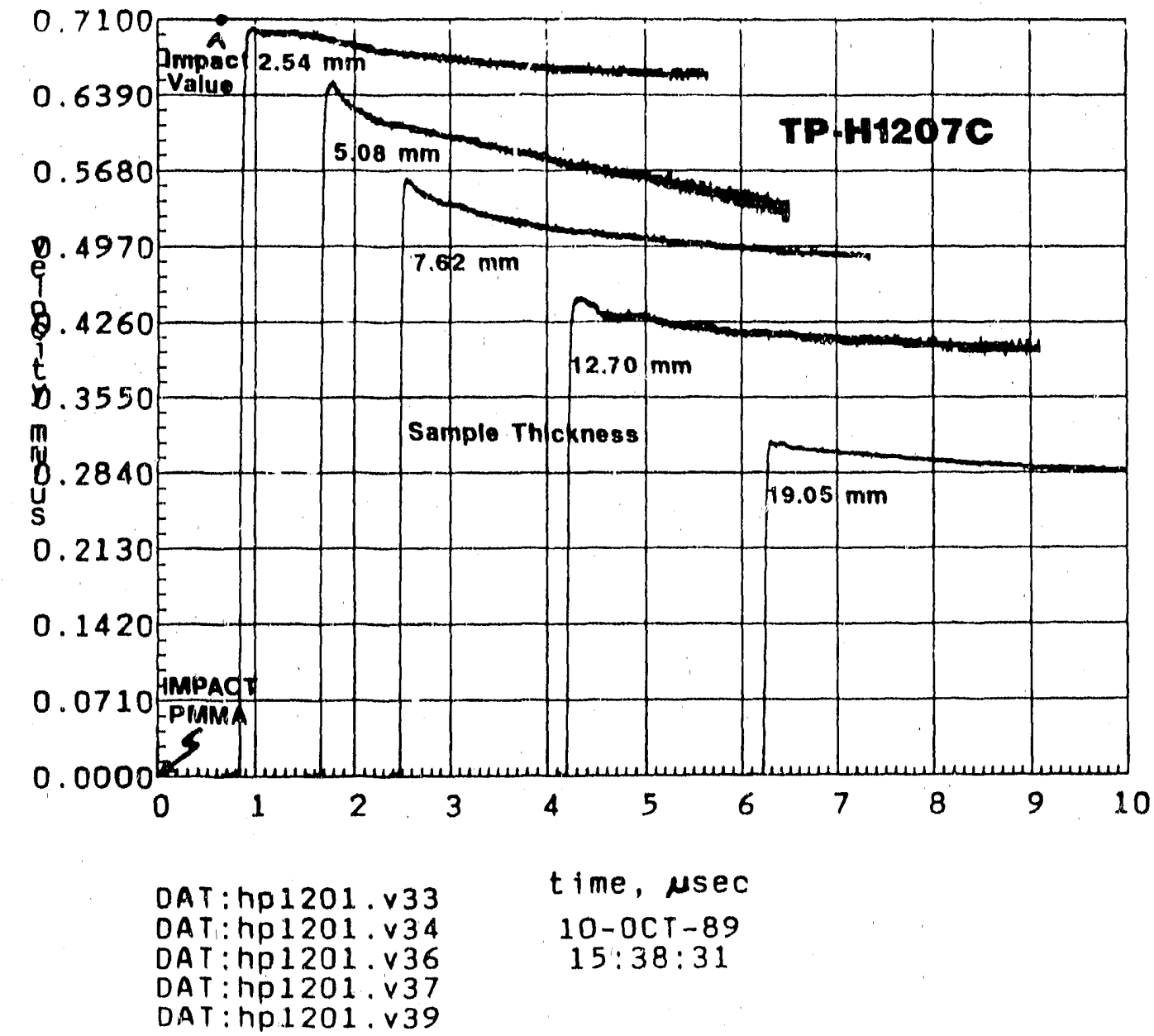

Figure 5. Plot of free-surface velocity with time for TP-H1207C samples af various thicknesses 


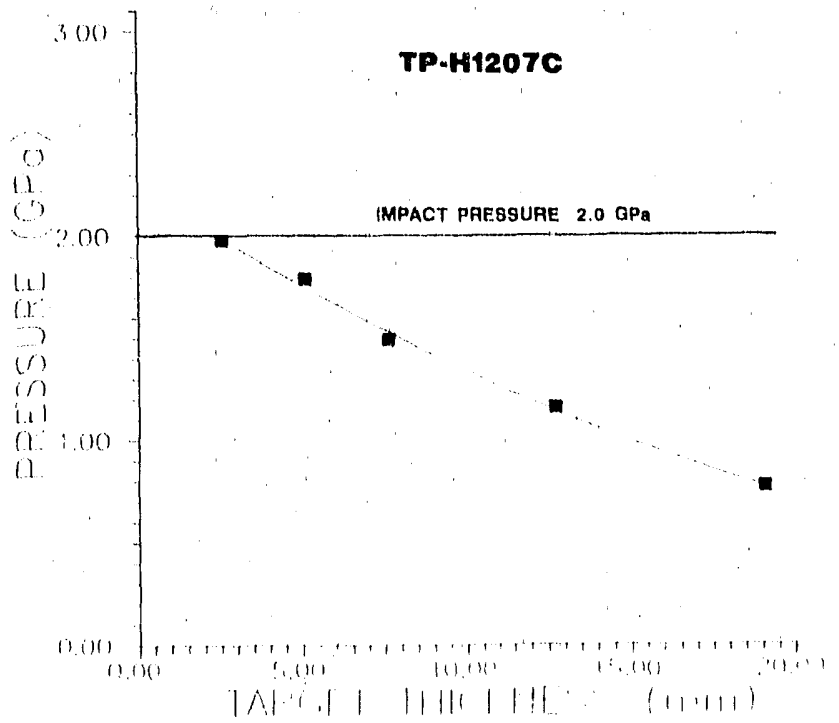

Figure 6. Attenuation profile for 'TP-H1207C

\section{UGS and the Energetic Propellant}

Figures 7 and 8 show the results for the attenuation experiments on two UGS and two energetic propellant samples, respectively. The samples had nominal thicknesses of 7.62 and $12.70 \mathrm{~mm}$, respectively. The recorded transit times for the passage of the shock wave through these materials were significantly longer than those calculated from the Hugoniot data, as shown in Table 3. Using the Hugoniot data measured proviously ${ }^{1}$ and the maximum particle ve. locity obtained from the data shown in Figures 7 and 8 results in the attenuation profile of rear-surface pressure versus material thickness as shown in Figure 9 for both UGS and the energetic propellant.

The pressure-versus-thickness profiles for all four materials are plotted in Figure 10. The similarity in attenuation for all four matorials can be easily seen from these plots.

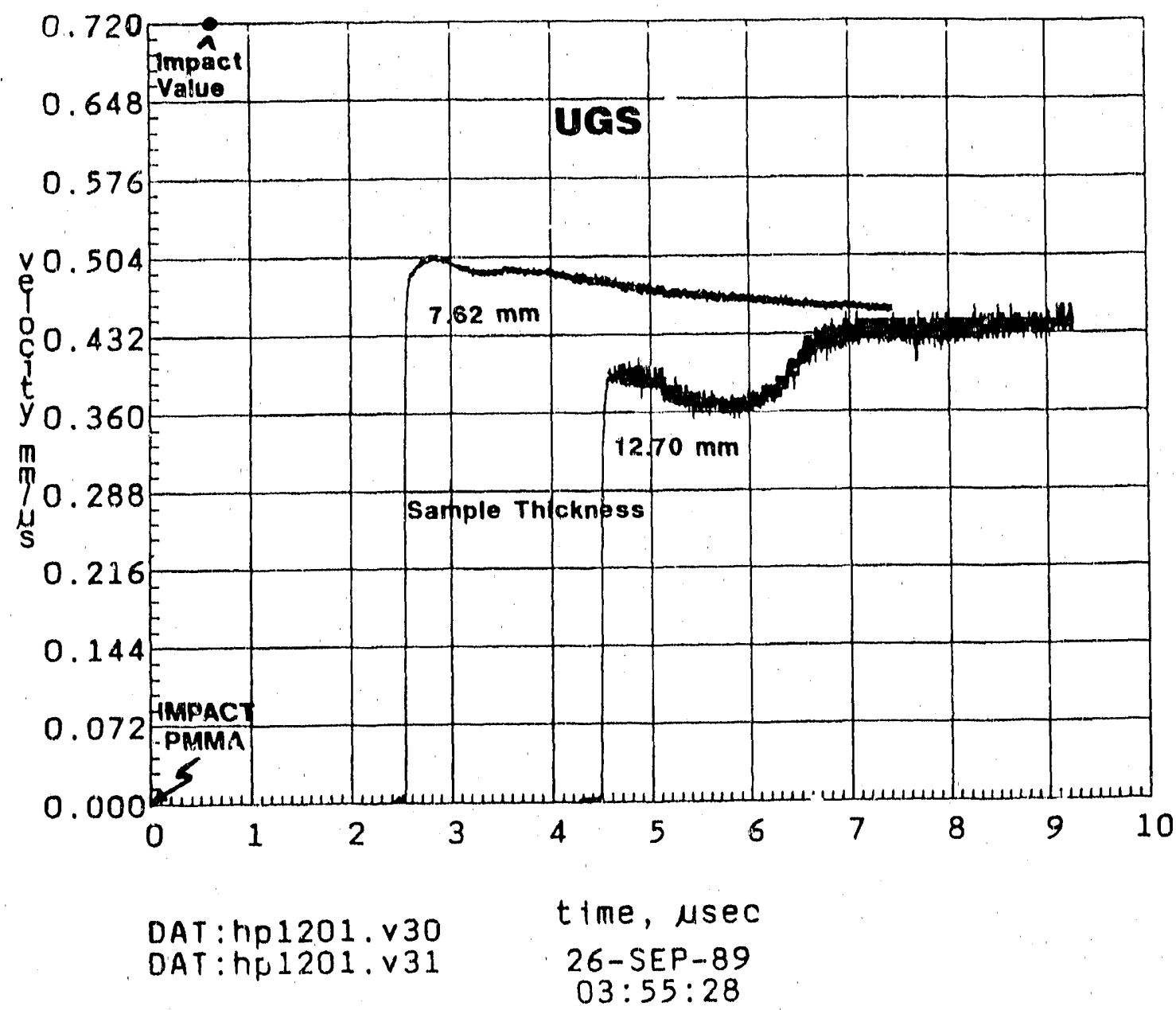

Figure 7. Plot of free-surface velocity with time for UGS samples of various thicknesses 


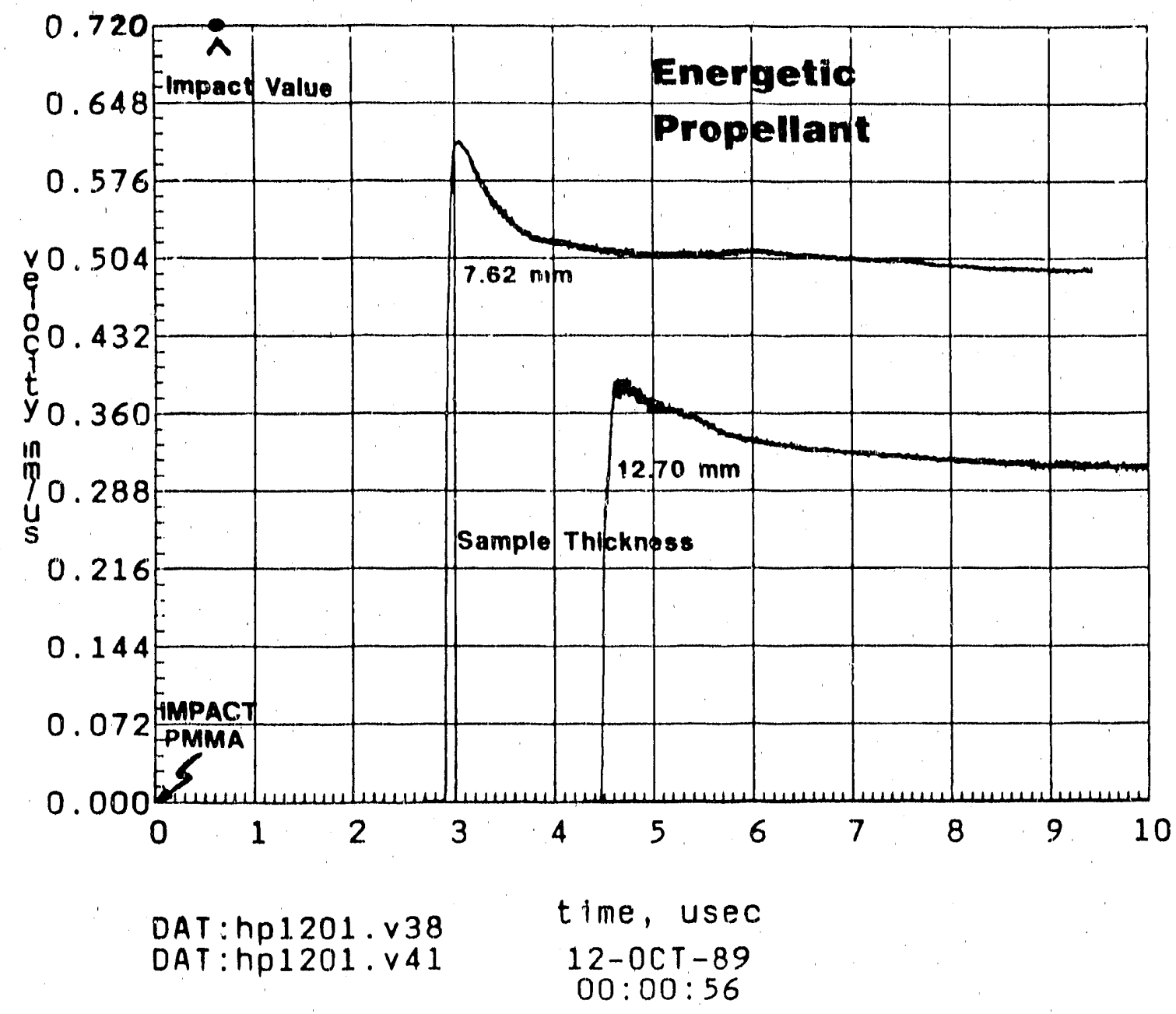

Figure 8. Plot of free-surface velocity with time for the energetic propellant samples of various thickness 


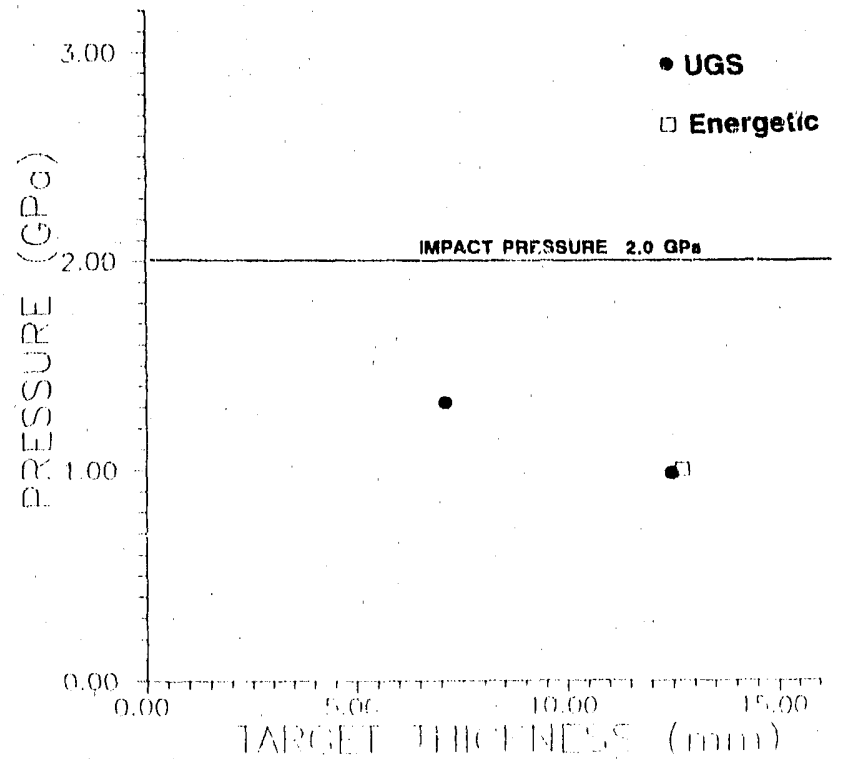

Figure 9. Attenuation profile for UGS and the energetic propellant

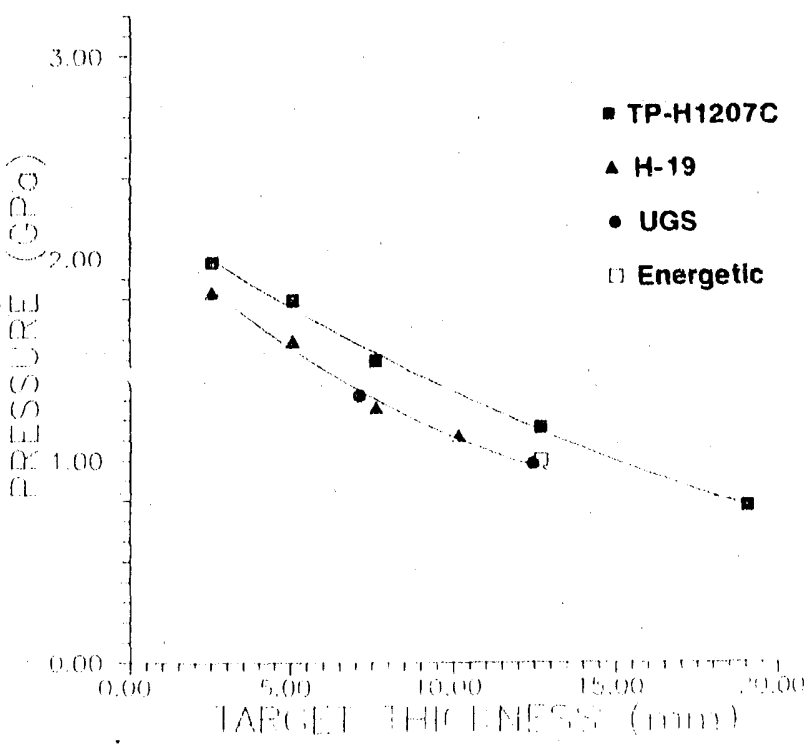

Figure 10. Attenuation profiles for H-19, TPH1.207C, UGS, and the snergetic propellant

\section{Discussion}

Two other recent investigations have measured the attenuation of a shock wave in $\mathrm{H}-19$. The first experiment was done by $\mathrm{SRI}^{12}$ during a study of the dynamic spall strength of $\mathrm{H}-19$ under a hydrostatic preload. An H-19 specimen disk was attached to the inside of a $1.27-\mathrm{cm}$-thick front wall of a cylindrical Lexan (polycarbonate) cup. A Lexan plug was screwed into the cup to form a pressure chamber. Compressed air was used to preload the specimen to an approximately hydrostatic condition. One stress gauge and one particle velocity gauge were positioned at the interface between the specimen and the Lexan wall. Another particle velocity gauge was located at the rear surface of the $0.75-\mathrm{cm}$-thick $\mathrm{H}-19$ specimen. The data from the particle velocity gauges for a shot with an input pressure of $1.2 \mathrm{GPa}$ on the $\mathrm{H}-19$ specimen are shown in Figure 11. If the Hugoniot parameters for $\mathrm{H}-19^{1}$ are used to convert the measured particle velocities to pressures at the front $(0.25 \mathrm{~mm} / \mu \mathrm{s}=1.24$ $\mathrm{GPa})$ and back $(0.195 \mathrm{~mm} / \mu \mathrm{s}=0.94 \mathrm{GPa})$ surfaces, the attenuation is $\sim 24 \%$ for the $0.75-\mathrm{cm}$-thick $\mathrm{H}-19$ sample. Figure 10 shows the attenuation profile for H-19 measured in this study. Extrapolating the curve to fit a $0.75 \mathrm{~cm}$-length change beginning at a pressure value of $1.24 \mathrm{GPa}$ gives a value of pressure of $\sim 0.85$ $\mathrm{GPa}$. This translates to an attenuation of $\sim 31 \%$, which is in experimentally good agreement with the SRI value of $\sim 24 \%$.

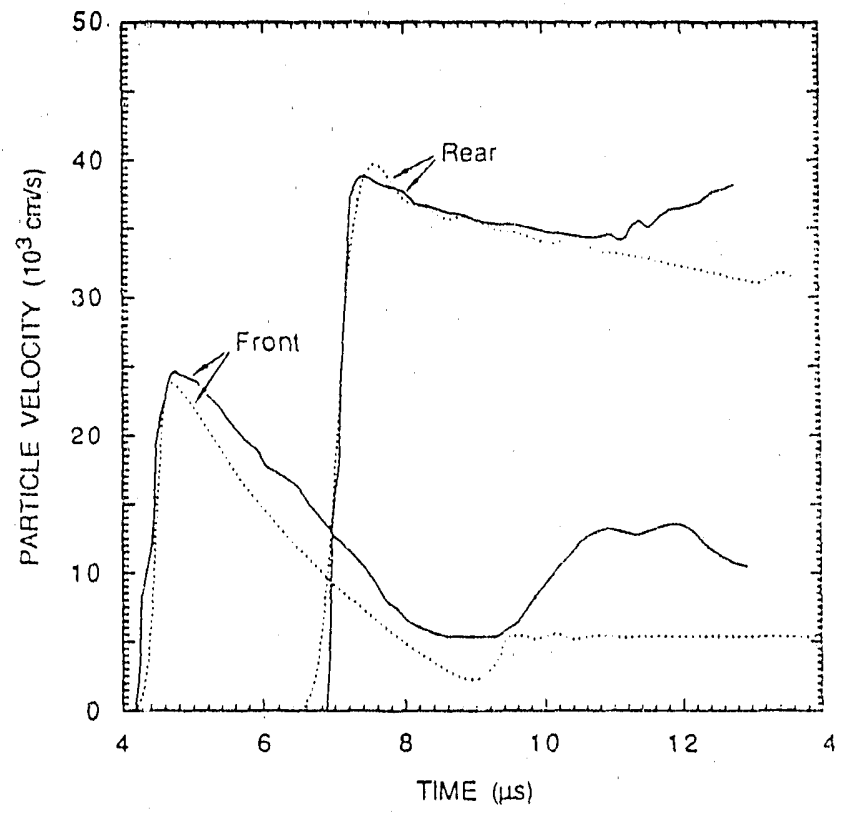

Figure 11. Particle velocity at the front and rear of the $\mathrm{H}-19$ target (SRI)

The second investigation on the attenuation of shock waves in $\mathrm{H}-19$ was done at K-Tech Corp. by Greb. ${ }^{13}$ This study also investigated the transmission of longer shock pulses through $\mathrm{H}-19$. The experimental configuration of the PMMA flyer plates/aluminum projectiles was different from the present work in that a quartz gauge was sandwiched between the PMMA flyer plate and aluminum projectile to measure impact stress. A mure significant difference was the use 
of carbon stress gauges at the rear of the specimens and between PMMA buffer and backer plates at $\mathrm{K}$-Tech instead of the VISAR measurements done at Sandia. The author strongly believes that the use of VISAR measurements for particle velocity and, subsequently, transmitted stress values maikes the analysis of the results relatively straightforward and understandable. Examining the K-Tech cosults, particularly for transmitted wave data, one can see that the gauge produced an additional response de: pending on the impact pressure. An estimate of the attenuation of the shock pulse by $\mathrm{H}-19$ can be made by subtracting the response of the gauge for a transmission shot at a given impact stress from the response of the gauge for an attenuation shot at a similar impact stress. The results for the K-Tech data using this procedure are given in Table 4. An average value for shock attenuation in $\mathrm{H}-19$ ir the stress range of 1.0 to $5.0 \mathrm{GPa}$ is $\sim 20 \%$ for a $3 \mathrm{~mm}$-thick specimen. This value agrees reasonably well with an estimated value of $18 \%$ from the pressure-sample thickness curve, Figure 4, from the present report for an impact stress of $\sim 2.0 \mathrm{GPa}$ through a $3-\mathrm{mm}$-thick sample.

Most other studies on propellants and explosives investigated the sensitivity and initiation properties of these materials rather than shock attenuation. However, shock attenuation in these materials can sometimes be extracted from the results. One example of this is given by the following analysis from data reported by $R$. Setchell on PBX-9404, ${ }^{14}$ a plasticbonded explosive. His report shows a plot of particle velocity versus time showing the shock front evolution at the rear surface of PBX-9404 specimens of various thicknesses which have been impacted by fused silica at $3.2 \mathrm{GPa}$. From the maximum particle velocity for a given specimen thickness and the Hugoniot relctionships for PBX-9404 and fused silica, the pressure can be calculated. These values are plotted as a function of specimen thickness in Figure 12. The attenuation curve determined for TP-H1207C is also shown on this figure for comparison. It appears that shock attenuation is more rapid in PBX-9404 than in TP.H1207C.

\section{Table 4. K-Tech Corp. Transmission Data}

\begin{tabular}{|c|c|c|c|c|c|c|}
\hline \multirow{2}{*}{\multicolumn{3}{|c|}{ Transmission }} & \multicolumn{4}{|c|}{ Attenuation } \\
\hline & & & \multirow[b]{2}{*}{$\begin{array}{l}\text { Impact } \\
\text { Stress } \\
(\mathrm{GPa})\end{array}$} & \multirow[b]{2}{*}{$\begin{array}{l}\text { Adjusted } \\
\text { Impact } \\
\text { Strers } \\
\left(G^{\top} \text { 'a) }\right.\end{array}$} & \multirow[b]{2}{*}{$\begin{array}{l}\text { Gauge } \\
\text { Stress } \\
\text { (GPa) }\end{array}$} & \multirow[b]{2}{*}{$\begin{array}{l}\text { Change } \\
\text { ("ii) }\end{array}$} \\
\hline $\begin{array}{l}\text { Impact } \\
\text { Stress } \\
(\mathrm{GPa})\end{array}$ & $\begin{array}{l}\text { Gauge } \\
\text { Stress } \\
\text { (GPa) }\end{array}$ & $\begin{array}{c}\text { Change } \\
\text { ("ii) }\end{array}$ & & & & \\
\hline 0.199 & 0.184 & 07.5 & 0.189 & '.175 & 0.168 & 04 \\
\hline 0.482 & 0.430 & 10.8 & 0.208 & 0.192 & 0.142 & 24 \\
\hline 1.104 & 0.830 & 24.8 & 0.520 & 0.463 & 0.289 & 33 \\
\hline 2.059 & 1.518 & 26.3 & $0.99^{\circ} \mathrm{j}$ & 0.761 & 0.632 & 17 \\
\hline 3.105 & 2.359 & 24.0 & 8.147 & 2.392 & 1.825 & 24 \\
\hline 6.178 & 4.909 & 20.5 & 5.283 & 4.200 & 3.503 & 17 \\
\hline
\end{tabular}




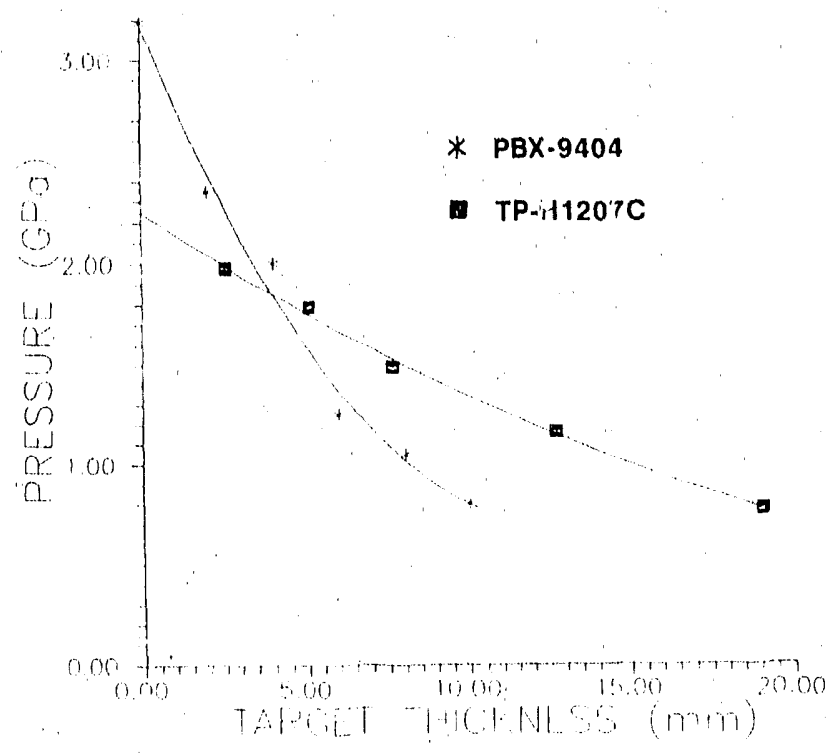

Figure 12. Attenuation profile for PBX-9404 from Setchell

\section{Summary}

A series of attenuation experiments on a composite propellant, an energetic propellant, and their simulants was recently completed on a light-gas gun. An initial impulse of $2.0 \mathrm{GPa}$ magnitude and $\sim 0.6 \mu \mathrm{s}$ duration was imposed upon samples of various thicknesses. VISAR was used to measure the free-surface velocit $y$ at the back of the samples, thus giving a curve of attenuated particle velocity versus sample thickness for each material. From the known Hugoniot parameters for each material, the attenuated particle velocities were convarted to attenuated shock pressures. A plot of attenuated pressures versus sample thickness is the shock attenuation for that material. Results showed that all four materials attenuated the shock wave very similarly. Material thicknesses of 3.0, $7.62,12.7$, and $19.0 \mathrm{~mm}$ attenuated the shock wave $\sim 16 \%, 33 \%, 50 \%$ and $66 \%$, respectively.

\section{References}

${ }^{1}$ L. J. Weirick, "Characterization of Booster-Rocket Propellants and Their Simulants," 1989 Ninth Symposium on Detonation, Volume I, Paper No. 157, Portland, OR, August 28 - September 1, 1989.

${ }^{2}$ L. R. Green, E. James, and $\mathrm{E}$. Lee, "The Detonability of Composite Propellants," 1986 JANNAF Propuision Systems Hazards Subcommittee Meeting Vol. 1, CPIA Pub. 446, March 1986.

${ }^{3}$ L. R. Green, E. James, E. Lee, E. Nidick, and E. Chambers, Air Force Propellant Study, UCID 19041, Lawrence Livermore National Laboratory, Livermore, CA, May 1981.

${ }^{4} \mathrm{P}$. Urtiew, E. James, and K. Scribner, High-Energy' Propellant Safety (HEPS) Program. Highlights, Volume I, UCID 17272-79-3, Lawrence Livermore National Laboratory, Livermore, CA, 1979.

${ }^{5} \mathrm{~L}$. Green, E. Chambers, E. James, E. Lee, and A. Weston, Summary Report on Experimental Work Using the 155-mm Gun, UCID 19424, Lawrence Livermore National Laboratory, Livermore, CA, June 1982.

${ }^{6} \mathrm{C}$. S. Speight, "Observation of Spallation and Attenuation Effacts in Aluminum From Free-Surface Velocity Measurements," Foulness Division Note FDN 4/71 (1971).

${ }^{7} \mathrm{M}$. E. Kipp and R. J. Lawrence, WONDY V-A OneDimensional Finite-Difference Wave Propagation Code, SAND81-0930, Sandia National Laboratories, Albuquer. que, NM, June 1982.

${ }^{8}$ W. F. Dunn to L. W. Poulter, "Extencled Ambient Cure of H-19 Propellant," Morton-Thiukol Inc., Wasatch Operations, Brigham City, Utah, memo dated 12 October 1987.

${ }^{9}$ S. A. Sheffield and D. W. Dugan, "Description of a New 63-mm Diameter Gas Gun Facility," Shock Waves in Condensed Matter, Y. M. Gupta, ed., Plenum Press, 1986.

${ }^{10} \mathrm{~L}$. M. Barker and R. E. Hollenbach, "Laser Interferometer for Measuring High Velocities of Any Reflecting Surface," J. Appl. Phys. 43:11 (November 1972).

${ }^{11} \mathrm{~W}$. F. Hemsing, "Velocity Sensing Interferometes (VISAR) Modification," Rev. Sci. Instrum. 50:1 (January 1979).

${ }^{12}$ B. S. Holmes, J. K. Gran, and D. C. Erlich, "Pulsed Laser Target Response (LTH-3)," Monthly Progress Re. port No. 12, SRI International, Menlo Park, CA, March 12, 1989.

${ }^{13}$ A. Greb, Shock Characterization of Two Simulant Propellants: $H-19$ and PR-1592, KTECH/TR-88/32, KTech Corp., Albuquerque, NM, November 1989.

${ }^{14} \mathrm{R}$. E. Setchell, "Short-Pulse Shock Initiation of Granular Explosives," Proceedings of the Seventh Symposium (International) on Detonation, Naval Surface Weapons Center, White Oak, MD, NSWC MP 82-334, 1982, p. 857. 

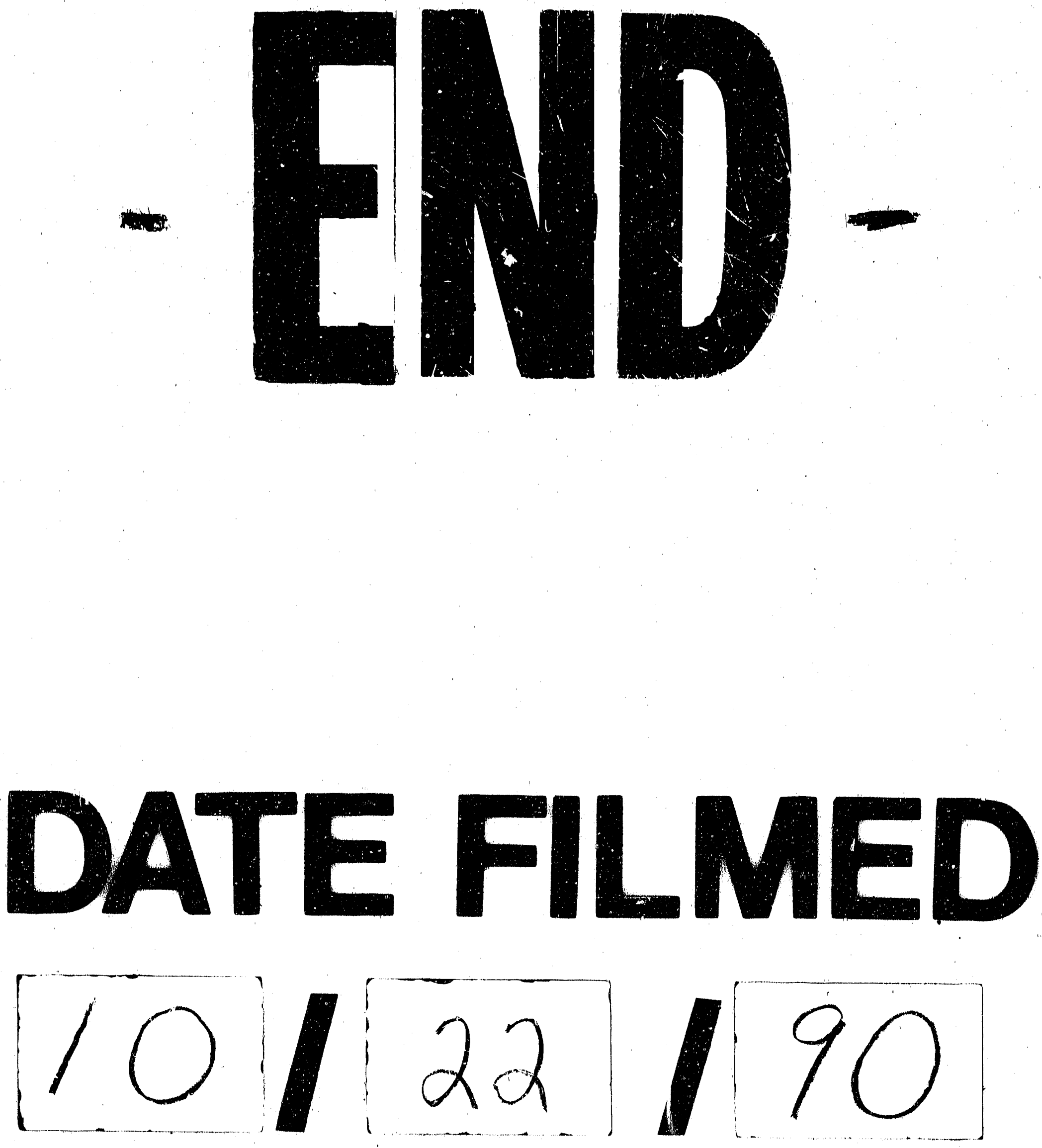
